\title{
A Long-Term Analysis of Spatiotemporal Change and Driving Factors on Poyang Lake during 1987-2019
}

\author{
Linye Zhu' ${ }^{1}$, Huaqiao Xing ${ }^{1 *}$, Dongyang $\mathrm{Hou}^{2}$, Yongyu Feng ${ }^{3}$, \\ Fengshuo Yang ${ }^{1}$, Peiyuan Qiu ${ }^{1}$ \\ ${ }^{1}$ School of Surveying and Geo-Informatics, Shandong Jianzhu University, Jinan, Shandong, China \\ ${ }^{2}$ School of Geosciences and Info-Physics, Central South University, Changsha, Hunan, China \\ ${ }^{3}$ Shandong Geographical Institute of Land Spatial Data and Remote Sensing Technology Center, Jinan, Shandong, China
}

Received: 31 August 2020

Accepted: 30 November 2020

\begin{abstract}
As the largest freshwater Lake in China, Poyang Lake plays an important role in regulating the water level of Yangtze River and maintaining the ecological balance of surrounding areas. Therefore, this study utilizes Google Earth Engine (GEE) geospatial technology to acquire 124 remotely sensed images to explore the spatial and temporal changes of the four seasons of Poyang Lake from 1987 to 2019. The official statistics from relevant cities are used to quantitatively reveal the main driving factors of water body changes in Poyang Lake. Temporally, the water body area of Poyang Lake shows an obvious downward trend in general. Spatially, the water body area of Poyang Lake shows a gradual decrease from the center of the lake to the surroundings. In 1987-1998, the water body area of Poyang Lake showed an increasing trend, with an increase of about $727.90 \mathrm{~km}^{2}$. From 1998 to 2006, the water body area of Poyang Lake mainly showed a decreasing trend, with a decrease of $401.58 \mathrm{~km}^{2}$. The water body area of Poyang Lake increased slowly during 2006-2017. Anthropogenic factors and natural factors have influenced the changes in water body area of Poyang Lake to a certain extent. This study can provide valuable supporting data for the comprehensive environmental management and flood hazard monitoring of Poyang Lake.
\end{abstract}

Keywords: surface water monitoring, spatiotemporal variation, time-series analysis, Google Earth Engine, driving forces

\section{Introduction}

Poyang Lake, the largest freshwater lake in China, exchanges water with the lower branch of the Yangtze

*e-mail: xinghuaqiao@126.com
River $[1,2]$. In recent years, the receding time of Poyang Lake has been advanced, and the water level has been low for many years and prolonged, which has caused problems such as deterioration of water environment and water ecology [3, 4]. Poyang Lake has experienced frequent flooding in the past decades, as well as the difficulty in predicting future floods 
in the area [5]. Thus, Monitoring the inter-annual and annual dynamic changes in the surface water of Poyang Lake is of great significance for flood prevention and mitigation in the middle reaches of the Yangtze River [6-8].

Although many scholars have been studying the spatial and temporal characteristics of the water body regions, according to the current literature, there are two main strategies for studying the spatial and temporal changes of water bodies. The first strategy is to use hydrological data (e.g., water level data) to analyze the water body changes in Poyang Lake, which cannot reveal the specific spatial location of water body changes and water level data are difficult to obtain $[9,10]$. With the rapid development of remote sensing technologies and the free availability of open-access satellite datasets, satellite imagery has provided a superior solution to traditional methods for monitoring surface water areas $[11,12]$. The second strategy is to monitor surface water changes in Poyang Lake using remote sensing data from various sensors and different water indices. For example, Hui et al. [13] used NDWI and MNDWI to map the water column of Poyang Lake from 6 multitemporal Landsat images in 1999 and 2000, and examined the annual spatial-temporal change. Feng et al. [14] documented and studied the shortterm and long-term characteristics of lake inundation using MODIS observations from 2000 to 2010 as the data source and the objective land-water delineation techniques as the estimation method. Han et al. [15] utilized 11 Landsat images to analyze the interannual variation of water body area in Poyang Lake during the winter from 1973 to 2013. Zeng et al. [16] revealed the intra-monthly variation by using Sentinel-1 SAR data for the observation period of Poyang Lake from October 2014 to March 2016. However, the study of long time series Poyang Lake water body change detection is limited by the storage and computational power of personal computers. Most of the above-mentioned studies analyze interannual changes in water bodies at 5-10 year intervals, or analyze monthly changes in water bodies over 3-5 years. Due to the relatively small amount of data, it may not be comprehensive enough to analyze driving factors or reveal change mechanisms.

To address the above problems, this paper utilizes the cloud-based Google Earth Engine platform [1719] (GEE, https://earthengine.google.org) to study the changes in water bodies of Poyang Lake over the thirty-three years from 1987 to 2019. Due to the strong seasonality of Poyang Lake, 124 images of the four seasons in Poyang Lake were collected. In order to conduct an in-depth analysis on the driving factors of water body changes in Poyang Lake, correlation analysis, principal component analysis and regression analysis were used to screen the driving factors of water body changes and determine the degree of influence.

The purpose of this study is to further understand the dynamics of Poyang Lake with improved the temporal resolution. It systematically reveals the temporal and spatial dynamic changes of the water bodies in Poyang Lake over the past thirty-three years, and analyzes the influence of natural and anthropogenic factors on the water body changes. This study is of great value for ecological construction planning of Poyang Lake, and provides solutions for long time series lake change detection in other parts of the world.

\section{Data and Methods}

\section{Study Area}

Poyang Lake is located in the northern part of Jiangxi Province $\left(28^{\circ} 38^{\prime} \sim 29^{\circ} 19^{\prime} \mathrm{N}\right.$ and $115^{\circ} 43^{\prime}$ $\sim 116^{\circ} 29^{\prime} \mathrm{E}$ ) (Fig. 1). Poyang Lake is an essential hydrological regulation area in the middle reaches of the Yangtze River, with a variety of land cover types and abundant natural resources in the lake area [20, 21]. Therefore, monitoring the surface water body area of Poyang Lake is of great ecological and hydrological importance in determining the inundation time and annual inundation of the marshland $[22,23]$.

\section{Datasets}

The imagery datasets between 1987 to 2019 are utilized for surface water extraction and water condition change detection (Table 1). Some of the Landsat images

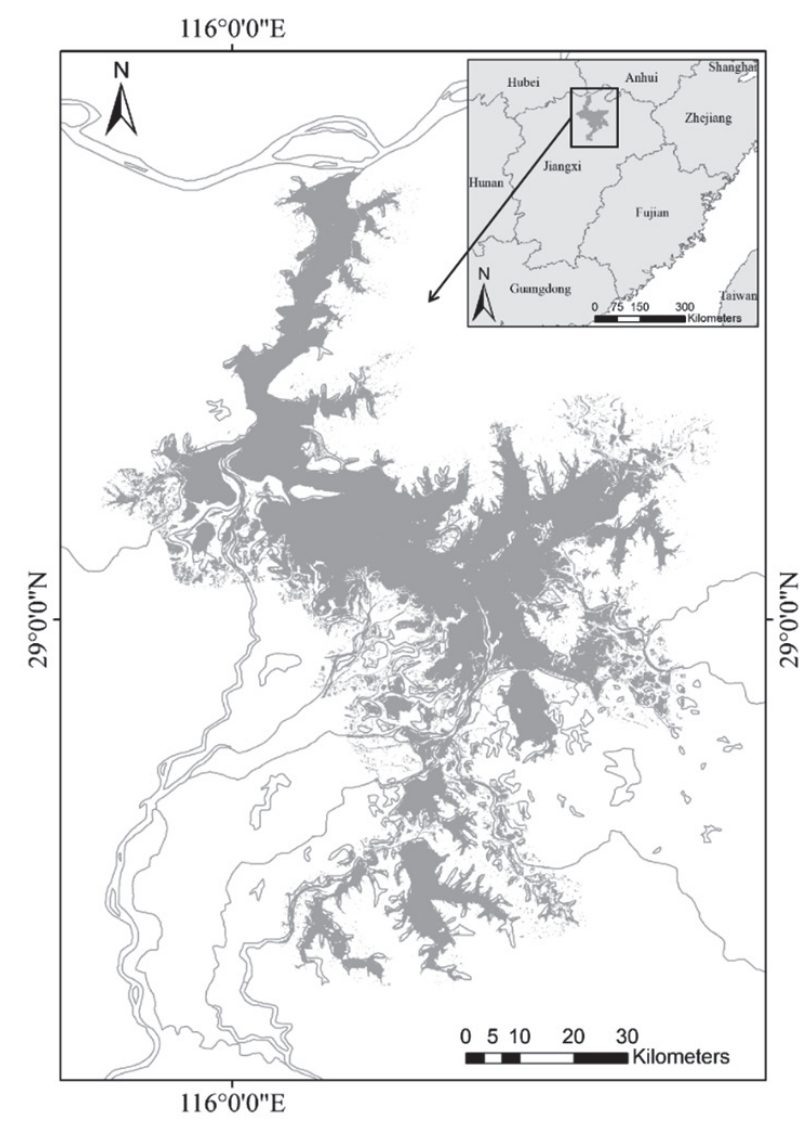

Fig. 1. The study area and location of Poyang Lake in China. 
Table 1. Description of datasets involved in the study.

\begin{tabular}{|c|c|c|c|c|c|c|}
\hline Year & Sensor & Path & Row & Resolution & Image Collection ID & Images \\
\hline $1987 \sim 2012$ & Landsat 5 TM & 121 & 40 & $30 \mathrm{~m}$ & LANDSAT/LT05/C01/T1_SR & 87 \\
\hline $2013 \sim 2019$ & Landsat 8 OLI & 121 & 40 & $30 \mathrm{~m}$ & LANDSAT/LC08/C01/T1_RT & 28 \\
\hline $2000 \sim 2012$ & MODIS & 121 & 40 & $500 \mathrm{~m}$ & MODIS/006/MOD09GA & 9 \\
\hline
\end{tabular}

suffered from huge cloudiness or even missing data, and the MODIS datasets were selected as supplementary datasets for these situations.

To analyze the seasonal variation of Poyang Lake, four scenarios per year were selected to represent the four seasons with the minimal cloud cover, i.e., spring (March 01-May 31), summer (June 01-August 31), autumn (September 01-November 30), and winter (December 01-February 28). Finally, 87 scenes of Landsat 5 TM from year 1987 to 2012, 28 scenes of Landsat 8 OLI from year 2013 to 2019, and 9 scenes of MODIS from year 2000 to 2012 were selected (Fig. 2). The above datasets have been orthorectified and atmospherically corrected to obtain surface reflectance. An automatic cloud masking procedure was applied using the C Function of Mask (CFMask; [24]) band included in the Landsat datasets.

\section{Methods}

\section{Water Extraction Using GEE}

GEE cloud computing platform is widely used in many large-scale and long-time remote sensed applications $[25,26]$. In this study, all the steps of data access and processing were conducted online, without any help of desktop-based software.

Four frequently-used water indices are calculated from the prepared Landsat data, i.e., NDWI, MNDWI, EWI, AWEI. The NDWI, proposed by Mcfeeters in 1996, is based on the normalized ratio index for the green and near-infrared bands, which is generally used to extract information about the water bodies in images [27]. Based on the NDWI analysis, an improved normalized difference water index, MNDWI, was proposed to distinguish between shadows and water bodies, which solves the problem of difficult to eliminate shadows in water extraction [28]. When extracting water systems in semi-arid areas, the enhanced waterbody index (EWI) can effectively suppress background noise such as buildings, bare land and vegetation [29]. An automatic water extraction index model (AWEI) was constructed [30]. The equations (1)-(4) are calculated as follows.

$$
\begin{gathered}
\text { NDWI }=\left(\rho_{\text {Green }}-\rho_{\text {NIR }}\right) /\left(\rho_{\text {Green }}+\rho_{\text {NIR }}\right) \\
M N D W I=\left(\rho_{\text {Green }}-\rho_{\text {MIR }}\right) /\left(\rho_{\text {Green }}+\rho_{\text {MIR }}\right)
\end{gathered}
$$

$$
E W I=\left(\rho_{\text {Green }}-\rho_{\text {NIR }}-\rho_{\text {MIR }}\right) /\left(\rho_{\text {Green }}+\rho_{\text {NIR }}+\rho_{\text {MIR }}\right)
$$

$$
\begin{aligned}
A W E I=4 * & \left(\rho_{\text {Green }}-\rho_{M I R}\right)-\left(0.25 * \rho_{N I R}\right. \\
& \left.+2.75 * \rho_{S W I R}\right)
\end{aligned}
$$

where $\rho_{\text {Green }}, \rho_{\text {NIR }}, \rho_{\text {MIR }}, \rho_{\text {SWIR }}$ represent the reflectance values of green, near-infrared, shortwave infrared bands of Landsat $5 \mathrm{TM}$, Landsat 8 OLI and MODIS, respectively.

After calculating the four water indices from Landsat datasets, the practical reference conditions of images are very complex due to the fact that the experimental datasets consist of sensors with different radiometric resolutions and a long time series [31]. Thus, to accurately extract the water body area, the

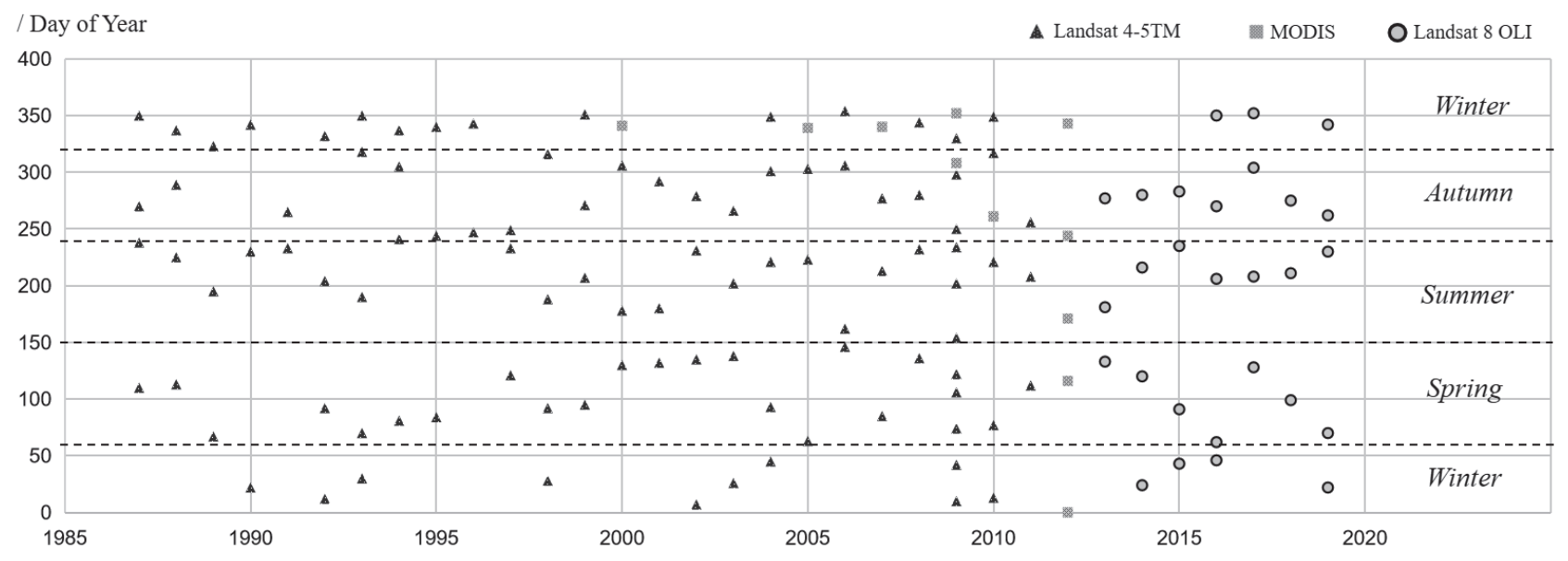

Fig. 2. Acquire time of Landsat datasets in this study. 
Table 2. Accuracy assessment of the four water indices.

\begin{tabular}{|c|c|c|c|c|}
\hline Water indices & OA & OR & CR & KC \\
\hline NDWI & 97.1955 & 4.14 & 0.64 & 0.9425 \\
\hline EWI & 96.2641 & 6.05 & 0.31 & 0.9238 \\
\hline AWEI & 95.0329 & 4.92 & 3.56 & 0.8977 \\
\hline MNDWI & 92.6927 & 3.63 & 8.35 & 0.8473 \\
\hline
\end{tabular}

optimal thresholds for the four water indices were selected by manually checking the match between the water surface results and the Landsat images.

\section{Accuracy Evaluation}

To evaluate the performance of the four water indices, 80-100 real samples were randomly selected from the high-resolution images (i.e., GeoEye-1 on Google Earth). The overall accuracy (OA), omission rate (OR), commission rate (CR) and kappa coefficient (KC) were used for accuracy assessment (Table 2). It can be observed that the accuracy of all four water indices is high, with OA exceeding 90\%, and the NDWI method is slightly more accurate than the other three methods. Therefore, the NDWI method was chosen as the extraction method for the water body area of Poyang Lake.

\section{Driver Analysis Methods for Poyang Lake}

Pearson's correlation analysis, principal component analysis, and regression analysis were performed by using Statistical Product and Service Solutions (SPSS 25) software. (1) Pearson's correlation analysis was used to yield the correlation coefficients between the driving factors and water body area [32]. (2) To eliminate the effects of different dimensions, the original data were standardized. The Kaiser-Meyer-Olkin (KMO) and Bartlett spherical tests were then applied to test the applicability of the indicator data for principal component analysis [33]. (3) The regression model was developed between the dependent variable and the driving factors by using the water body area of Poyang Lake as the dependent variable [34].

\section{Results and Discussion}

\author{
Temporal and Spatial Variation Analysis \\ of Poyang Lake
}

\section{Temporal Characteristics of Water Bodies}

The change in the water body area of Poyang Lake has shown a declining trend to some extent over the past thirty-three years (Fig. 3). Due to the floods that occurred in 1995, 1996, 1998, and 1999, the water surface area of Poyang Lake showed an upward trend. After entering 2000, Poyang Lake was dominated by the dry season. The sudden decrease in the area of Poyang Lake in the winter of 2003 coincided with the storage time of the Three Gorges Dam in that year. The decrease in lake level may be related to the dry season storage of water at the Three Gorges Dam [35]. The total water body area of Poyang Lake was relatively large in 2010. After severe flooding in June 2010, the Poyang Lake experienced a severe drought in 2011 [36]. Combined with relevant data analysis, it is found that the total rainfall and inflow are larger in years with the larger water body area [37].

The area of water bodies in Poyang Lake mainly showed an increasing trend from 1987 to 1998 (Fig. 4). The area of water bodies in Poyang Lake increased by about $727.90 \mathrm{~km}^{2}$. The area of the tributary water systems on the east, west and south sides of Poyang Lake all increased to different degrees.

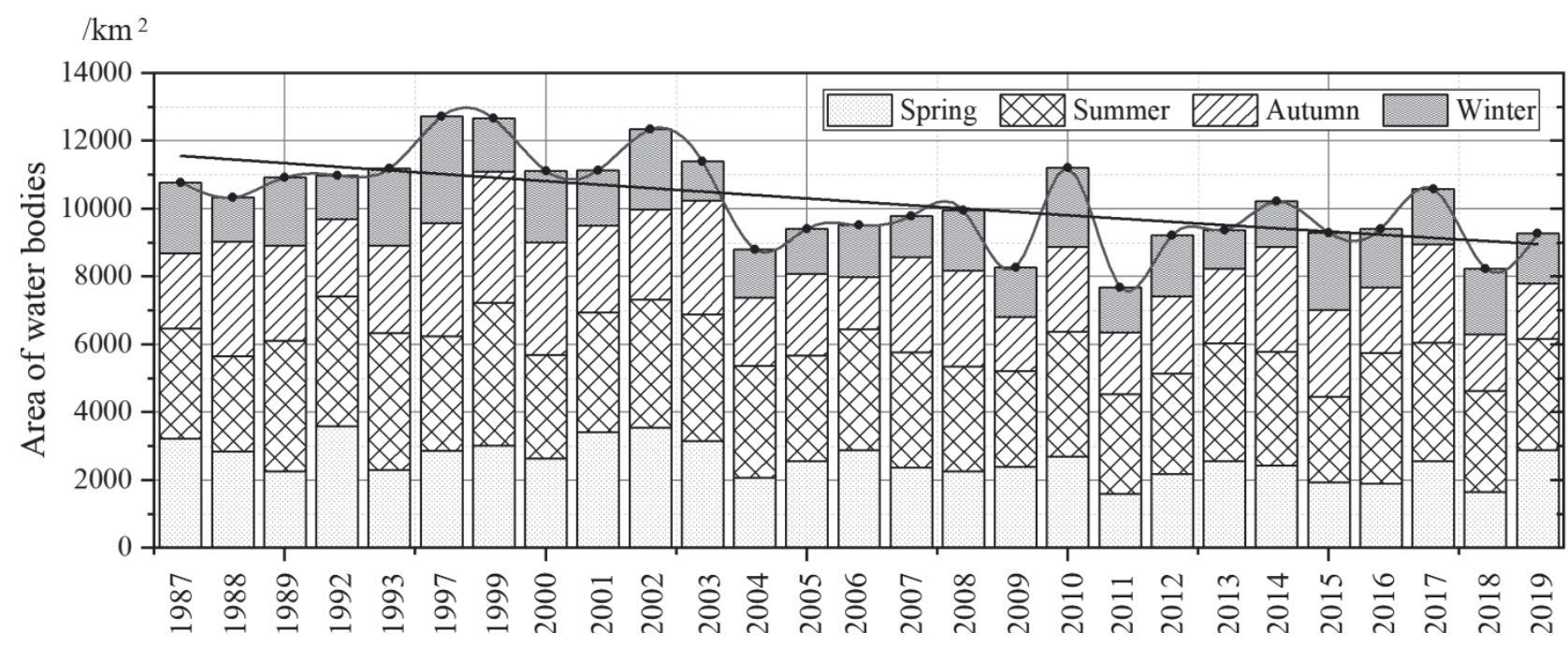

Fig. 3. Statistical charts of surface water area of Poyang Lake during 1987-2019 with four seasons. 
a) $116^{\circ} 0^{\circ} 0^{\mathrm{E}} \mathrm{E}$

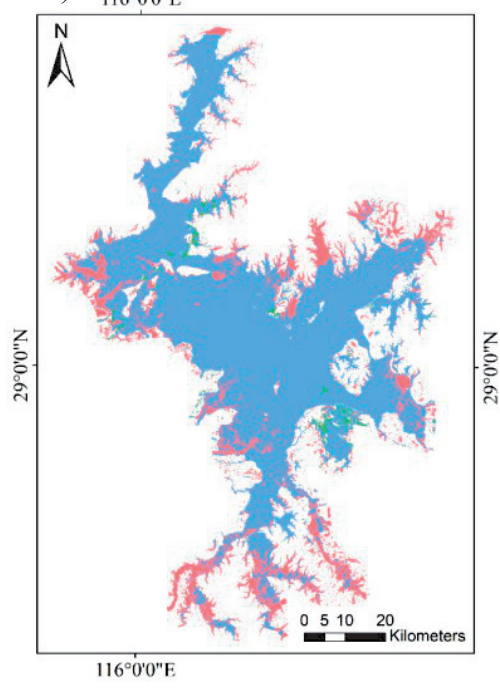

b) $116^{\circ} 0^{\circ} \mathrm{E} \mathrm{E}$

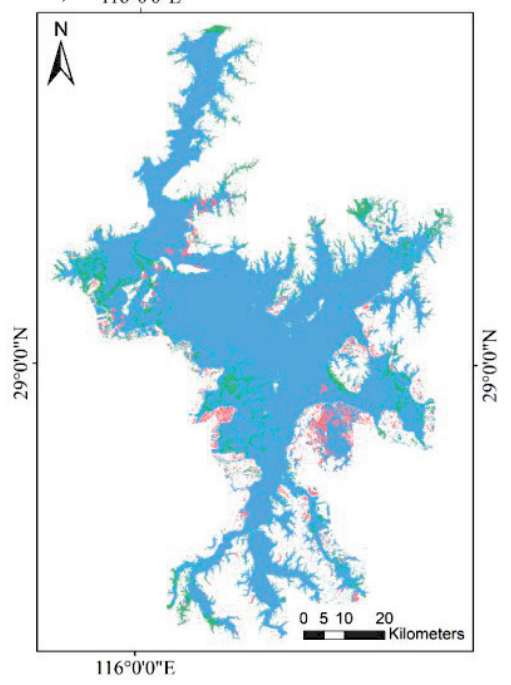

c) $116^{\circ} 0^{\circ} 0^{\prime \prime} \mathrm{E}$

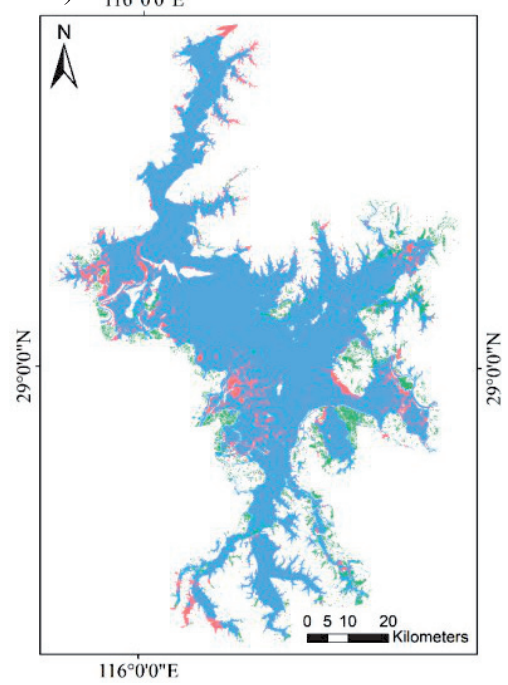

Fig. 4. Changes in the water body area of Poyang Lake (summer data calculated at 10-year intervals). a) 1987-1998; b) 1998-2006; c) $2006-2017$.

Poyang Lake suffered from frequent flooding disasters from 1987 to 1998, which led to the increase of water body area during the year. From 1998 to 2006, the area of water bodies in Poyang Lake mainly displayed a decreasing trend, with a decrease of $401.58 \mathrm{~km}^{2}$. It was mainly concentrated in the flood relief area of the eastern and western tributaries in Poyang Lake. The reason is that after 1998, the precipitation of Poyang Lake basin had decreased significantly. During the past 10 years of development, the original young forests had matured, and the forest resources had played a weakening role in the runoff of the Poyang Lake basin. From 2006-2017, the area of Poyang Lake decreased by $69.63 \mathrm{~km}^{2}$. The runoff from Poyang Lake decreased, which was associated with urbanization and increased urban impervious area.

\section{Spatial Characteristics of Water Bodies}

Due to the interaction of climate change, natural evolution and anthropogenic factors, the seasonal characteristics of the water body area of Poyang Lake are particularly obvious. By calculating the water body area data of Poyang Lake from 1987 to 2019, the water body area of Poyang Lake is larger in summer, with an average area of $3418.78 \mathrm{~km}^{2}$ (Table 3). Poyang Lake has the smallest water body area in winter, with an average area of $1730.02 \mathrm{~km}^{2}$. The water body area of Poyang Lake is approximately the same in spring and autumn.

The previous analysis of temporal and spatial characteristics in wet and dry abrupt changes is mostly based on statistical data or site monitoring data. According to the interpreted big data on the historical changes in the water body area of Poyang Lake, and combined with the administrative areas of counties and villages, it is discovered that the spatial location of the annual flooding is concentrated in the circular
Table 3. Average surface water area of four seasons during 19872019.

\begin{tabular}{|c|c|c|c|c|}
\hline Season & Spring & Summer & Autumn & Winter \\
\hline $\begin{array}{c}\text { Average area } \\
\left(\mathrm{km}^{2}\right)\end{array}$ & 2603.07 & 3418.78 & 2594.87 & 1730.02 \\
\hline
\end{tabular}

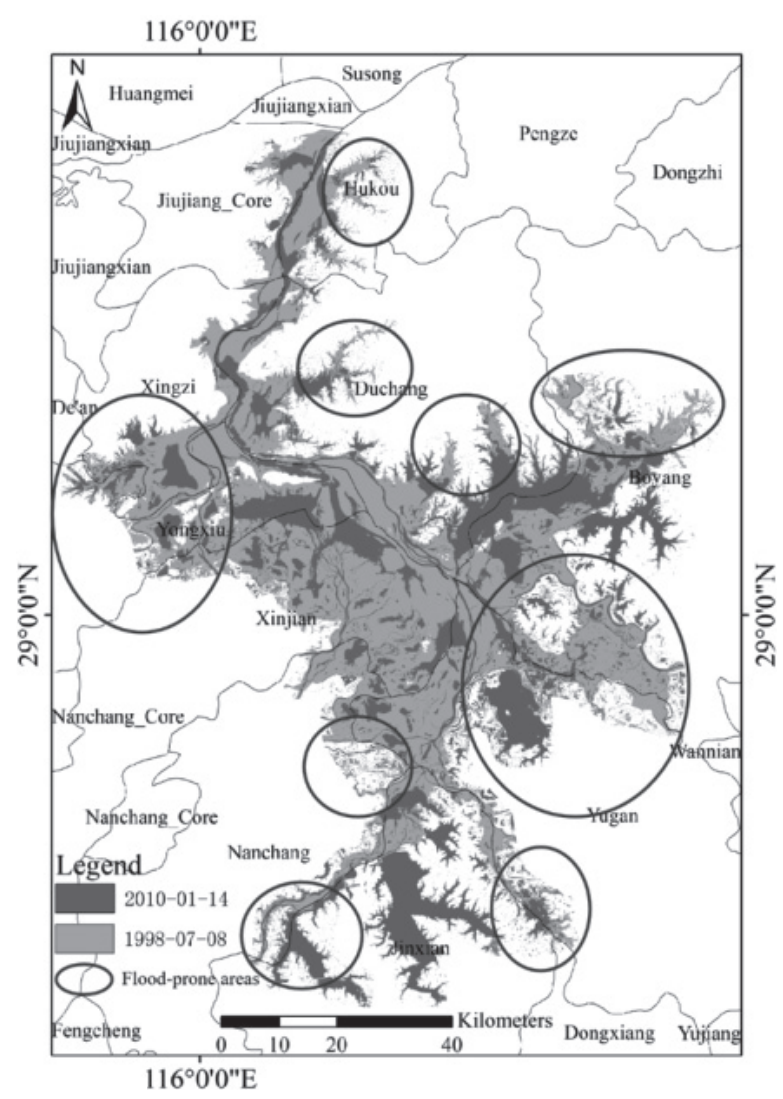

Fig. 5. Spatial and temporal characteristics of dry and wet abrupt transition in Poyang Lake. 


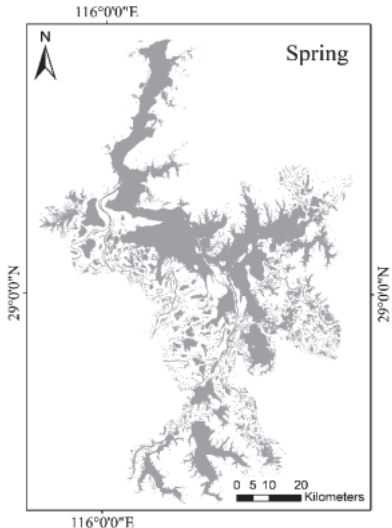

Spring (2009-03-16)

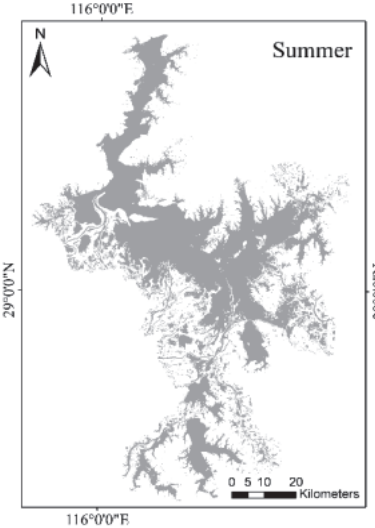

Summer (2009-06-04)

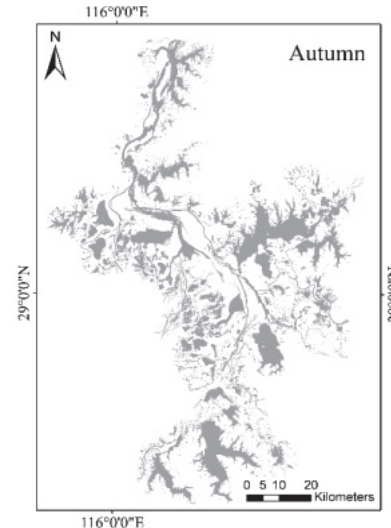

Autumn (2009-10-26)

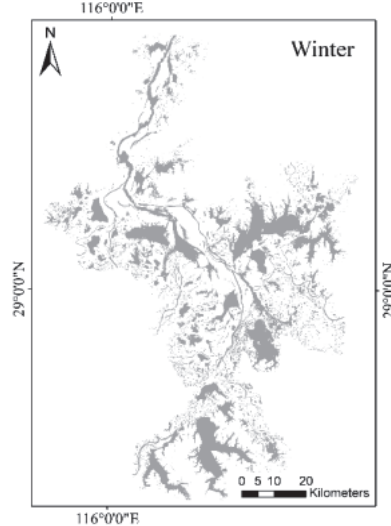

Winter (2010-01-14)

Fig. 6. The surface water maps of four seasons in Poyang Lake.

areas (Fig. 5). The areas along the lake such as Jiujiang City, Hukou County, Duchang County, Xingzi County, Yongxiu County, Xinjian County, Nanchang County, Jinxian County, Yugan County, and Poyang County have experienced different degrees of flooding. In autumn, the drought condition of Poyang Lake usually begins to shrink first from the southwest direction of Poyang Lake. In winter, only the central, southern and eastern parts of Poyang Lake are left. In spring, the surface area of the lake starts to increase, the central and northern part of the lake is replenished, and a small area of water surface also appears in the southwest direction. In particular, the south side of Junshan Lake is a closed water bodies, which remains essentially unchanged in area, and its left side is partially preserved due to its low terrain (Fig. 6) [38]. The spatial changes in the Poyang Lake basin can provide basic data for the government's flood mitigation and wetland protection, and help mitigate and regulate flood and drought hazards in the Poyang Lake basin.

\section{Analysis of the Driving Forces for Spatio-Temporal Water Body Area Variation}

\section{Links between Driving Factors and Water Body Area Variation}

This paper analyzes the driving factors of changes in the water bodies of Poyang Lake from two aspects, as follows.
The natural factors that influence the changes in water body area include recharge type, temperature and precipitation. The annual temperature and annual precipitation of Poyang Lake from 1987 to 2015 were obtained through the Resource and Environment Data Cloud platform (http://www.resdc.cn/Default.aspx). The average monthly flow and average monthly water level of Poyang Lake from 2000 to 2007 were collected from the China Lake Scientific Database (http://www. lakesci.csdb.cn/). The t-test for the water body area and the average annual precipitation, average monthly water level, average monthly flow was passed with a confidence level of 0.05 . It indicates that the average annual precipitation, average monthly water level, and average monthly flow have a positive effect on the change of water body area in Poyang Lake (Table 4).

Due to the complexity and diversity of anthropogenic factors, this paper mainly selects representative factors such as economy, population and urbanization to study the influence of anthropogenic factors on the Poyang Lake basin. The relevant data from 2000 to 2019 were obtained by consulting the Jiangxi Provincial Statistical Yearbook (http://tjj.jiangxi.gov.cn/). According to the results of the t-test of the confidence level (Table 5), the anthropogenic factors that have a negative impact on the water body area of Poyang Lake are as follows: Total Population $>$ Gross Fishery Product $>$ Gross Product of Agriculture, Forestry, Livestock and Fishery $>$ Gross Domestic Product per capita $>$ Gross Domestic Product $>$ Floor Space of Buildings Completed.

Table 4. Correlation between water body area and natural factors.

\begin{tabular}{|c|c|c|c|c|}
\hline \multirow{2}{*}{ Natural factor } & \multirow{2}{*}{ Pearson correlation coefficient } & \multicolumn{3}{|c|}{ t-Test } \\
\hline & & $\mathrm{P}$ & $\mathrm{t}$ & Statistical Significance (sig) \\
\hline Average Annual Precipitation & 0.511 & $\mathrm{P}<0.05$ & -15.436 & 0.000 \\
\hline Average Annual Temperature & -0.252 & $\mathrm{P}>0.05$ & -42.179 & 0.000 \\
\hline Average Monthly Water Level & 0.928 & $\mathrm{P}<0.05$ & -18.259 & 0.000 \\
\hline Average Monthly Flow & 0.596 & $\mathrm{P}<0.05$ & 4.185 & 0.000 \\
\hline
\end{tabular}


Table 5. Correlation between water body area and anthropogenic factors.

\begin{tabular}{|c|c|c|c|c|c|}
\hline \multirow{2}{*}{ Category } & \multirow{2}{*}{ Anthropogenic factor } & \multirow{2}{*}{$\begin{array}{l}\text { Pearson correlation } \\
\text { coefficient }\end{array}$} & \multicolumn{3}{|c|}{$\mathrm{t}$-Test } \\
\hline & & & $P$ & $\mathrm{t}$ & sig \\
\hline \multirow{7}{*}{ Economic } & Gross Domestic Product per capita & -0.552 & $\mathrm{P}<0.05$ & -30.116 & 0.000 \\
\hline & Gross Domestic Product & -0.543 & $\mathrm{P}<0.05$ & 6.651 & 0.000 \\
\hline & Gross Product of Construction Industry & -0.437 & $\mathrm{P}>0.05$ & 4.273 & 0.001 \\
\hline & Gross Industrial Product & -0.464 & $\mathrm{P}>0.05$ & 4.512 & 0.000 \\
\hline & Gross Fishery Product & -0.564 & $\mathrm{P}<0.05$ & 8.086 & 0.000 \\
\hline & $\begin{array}{c}\text { Gross Product of Agriculture, Forestry, Live- } \\
\text { stock and Fishery }\end{array}$ & -0.559 & $\mathrm{P}<0.05$ & 8.712 & 0.000 \\
\hline & Urban Fixed Assets & -0.408 & $\mathrm{P}>0.05$ & 4.553 & 0.000 \\
\hline Population & Total Population & -0.605 & $\mathrm{P}<0.05$ & 97.101 & 0.000 \\
\hline Urbanization & Floor Space of Buildings Completed & -0.520 & $\mathrm{P}<0.05$ & 2.137 & 0.047 \\
\hline
\end{tabular}

Through the study of the water body changes in Poyang Lake over the past thirty-three years, the water body changes in Poyang Lake are mainly composed of natural factors and anthropogenic factors. The natural factors are mainly influenced by climate change and the surrounding rivers (Yangtze River, Min jiang River, etc.). The details are as follows: after March, influenced by the connection of the five rivers, Poyang Lake starts to enter the lake flood season. April-June is the main flood season of the Poyang Lake basin. In July, the flood season in the Poyang Lake basin ends with a significant decrease in precipitation, but July is the main flood season of Yangtze River basin. Due to the influx of Yangtze River water into the lake, the water body area of Poyang Lake reaches the annual maximum. With the arrival of the high temperature and autumn dry season, the precipitation of Poyang Lake decreases dramatically, but due to the influence of the Yangtze River, the water level of Poyang Lake decreases less than the impact of reduced precipitation. In September, the water level of Poyang Lake remains high for a long time under the influence of the Yangtze River, and in October, the water level shows a downward trend. From December to February of the following year, Poyang Lake appears a dry period. In general, the water level of Poyang Lake is most likely to reach the lowest value in January or February.

The anthropogenic factors for changes in the water body area of Poyang Lake mainly include policy and economic factors [39]. The construction of Three Gorges Dam in 1994 had certain influence on the change of water body area in Poyang Lake. As Poyang Lake belongs to the middle and lower reaches of the Yangtze River, changes in the water level of the Yangtze River will directly affect the flow in and out of Poyang Lake. If the water level of the Yangtze River drops, its "emptying" effect will cause the water level of the lake to drop and the water surface area of the lake to shrink. After the storage of the Three Gorges Dam, the amount of water from the Yangtze River decreases, and the drop in water level increases the difference between the Yangtze River and Poyang Lake, which accelerates the outflow of water from Poyang Lake. The above-mentioned situations also have an impact on the amount of water flowing into Poyang Lake. From 1987 to 2019, changes in the GDP and industrial structure of the Poyang Lake basin have played a role in the changes in the water body area of Poyang Lake. In 2009, with the "Poyang Lake Ecological Economic Zone Plan" becoming a national strategy, the Poyang Lake City Group and related industries have become the most important industries in China [40]. With the improvement in the level of urbanization, the wetlands in the Poyang Lake basin have been converted into construction land and farmland. Since 2001, with the increase in industrialization and the use of water for industrial production, sand mining activities in Poyang Lake have intensified, resulting in a decrease in the lake's water level. As a result, a large amount of water in the lake has been recharged to the groundwater, which in turn has exacerbated the shrinkage of the Poyang Lake's water body area.

\section{Principal Component Analysis of Poyang Lake Basin}

In this paper, principal component analysis was performed on the Poyang Lake basin. The Bartlett spherical test statistic is 520.032 with 55 degrees of freedom, less than the significance level of 0.05 , and the KMO value is $0.826>0.7$, indicating that it is suitable for factor analysis. The results of principal component analysis (Table 6) showed that the cumulative contribution of the first and second principal components reached $94.464 \%$. Thus, only two principal components need to be extracted to summarize most of the information about the driving factors. 
Table 6. The results of principal component analysis in Poyang Lake basin.

\begin{tabular}{|c|c|c|c|}
\hline Component & Total & \% of Variance & Cumulative $\%$ \\
\hline 1 & 8.992 & 81.746 & 81.746 \\
\hline 2 & 1.399 & 12.719 & 94.464 \\
\hline 3 & 0.464 & 4.218 & 98.683 \\
\hline 4 & 0.117 & 1.067 & 99.750 \\
\hline 5 & 0.017 & 0.152 & 99.901 \\
\hline 6 & 0.006 & 0.056 & 99.957 \\
\hline 7 & 0.002 & 0.022 & 99.979 \\
\hline 8 & 0.001 & 0.013 & 99.992 \\
\hline 9 & 0.000 & 0.004 & 99.996 \\
\hline 10 & 0.000 & 0.004 & 100.000 \\
\hline 11 & 0.000 & 0.004 & 100.000 \\
\hline
\end{tabular}

Varimax was applied to rotate the factors and calculated the factor loadings. The anthropogenic factors had higher loads on the first principal component, and the natural factors had higher loads on the second principal component (Table 7). It can be concluded that the driving factors of the first principal component in Poyang Lake basin are population, economic and urbanization factors, and the driving factors of the second principal component are average annual temperature and average annual precipitation.

\section{General Relationship of Water Body Area and Water Level, Temperature, Precipitation}

The water body area-water level model and the water body area-precipitation-temperature model were established based on the relevant data of Poyang Lake (Table 8). By establishing the water body area-water level model and the water body area-precipitationtemperature model, it can provide new methods for the dynamic monitoring of water body area under severe meteorological conditions, and solve the problem of not being able to monitor lake surface water information in a timely manner in the absence of data.

Where $A_{o b s}$ is the water body area $\left(\mathrm{km}^{2}\right)$ extracted from the remote sensing image; $A_{\text {sim }}$ is the water body area $\left(\mathrm{km}^{2}\right)$ for regression simulation; $R_{\text {Aobs-Asim }}$ is the correlation coefficient between the remote sensing observation and the simulated water body area; $w$ is the average monthly water level (m); $T$ is the average annual temperature $\left({ }^{\circ} \mathrm{C}\right) ; P$ is average annual precipitation $(\mathrm{mm}) ; \Sigma$ is the cumulative symbol for each year.

\section{Conclusions}

The availability of the archived Landsat images and the usability of the GEE platform provide

Table 7. Factor loading matrix after rotation in Poyang Lake basin.

\begin{tabular}{|c|c|c|c|}
\hline \multirow{2}{*}{$\begin{array}{c}\text { Category } \\
\text { Factor }\end{array}$} & Index & $\begin{array}{c}\text { First Principal } \\
\text { Component }\end{array}$ & $\begin{array}{c}\text { Second Principal } \\
\text { Component }\end{array}$ \\
\hline \multirow{3}{*}{ Climate } & Average Annual Precipitation & 0.371 & -0.784 \\
\cline { 2 - 4 } & Average Annual Temperature & 0.143 & 0.881 \\
\hline \multirow{2}{*}{ Population } & Total Population & 0.981 & 0.048 \\
\hline Urbanization & Floor Space of Buildings Completed & 0.992 & 0.005 \\
\hline \multirow{3}{*}{ Economic } & Urban Fixed Assets & 0.993 & 0.010 \\
\cline { 2 - 4 } & Gross Product of Agriculture, Forestry, Livestock and Fishery & 0.993 & 0.040 \\
\cline { 2 - 4 } & Gross Industrial Product & 0.992 & -0.015 \\
\cline { 2 - 4 } & Gross Product of Construction Industry & 0.985 & -0.016 \\
\cline { 2 - 4 } & Gross Domestic Product & 0.994 & 0.015 \\
\cline { 2 - 4 } & Gross Fishery Product & 0.995 & 0.058 \\
\hline
\end{tabular}

Table 8. Regression model of water body area, water level, temperature and precipitation.

\begin{tabular}{|c|c|c|c|}
\hline Base Period & Regression Formula & Goodness of Fit & $R_{\text {Aobs }-A s i m}$ \\
\hline $2000-2007$ & $A_{\text {sim }}=-8.57 \times w^{2}+433.59 \times w-1427.90$ & 0.8750 & 0.9354 \\
\hline $1987-2015$ & $\sum A_{\text {sim }}=211.51+1.203 \times \sum P+32.58 \times \sum T$ & 0.9994 & 0.9997 \\
\hline
\end{tabular}


an advanced approach for monitoring long-term and large-scale environmental and land cover changes. In this paper, a successful study of surface water changes in Poyang Lake from 1987 to 2019 was carried out using a large number of Landsat images and the GEE platform, combining yearbook statistics to analyze the driving factors of water body area changes in Poyang Lake. The results showed the following:

(1) From the temporal perspective, the water body area of Poyang Lake shows a clear decreasing trend. From 1987 to 1998, Poyang Lake had frequent floods, and the water body area showed an increasing trend, with the area of water bodies in Poyang Lake increased by about $727.90 \mathrm{~km}^{2}$. After 2000, Poyang Lake entered the low-water period. In 1998-2006, Poyang Lake decreased the water body area by $401.58 \mathrm{~km}^{2}$. In 2006-2017, the water body area of Poyang Lake increased slowly. During 1987-2019, the water body area of Poyang Lake was relatively small in 2009 and 2011.

(2) From the spatial perspective, the area of the water bodies gradually decreases from the center of the lake to the surrounding area. It shows fluctuations in area centered on the northern estuary and the southern main lake area, but some areas are basically stable, such as Junshan Lake and the southern lake area. Generally speaking, the lake surface is vast during the flood season, and the areas along the lake such as Nanchang County, Xinjian County and Poyang County are prone to flooding, while only a few water belts are left in the dry season. Using remote sensing to monitor lake changes is different from traditional statistical data, which not only investigates the dynamic changes of the Poyang Lake, but also indicates the spatial location of the changed areas.

(3) The results of the correlation analysis show that water level, precipitation and monthly flow are positively correlated with changes in water body area. Temperature has little effect on the changes of water bodies in Poyang Lake. The anthropogenic factors are negatively correlated with the changes of water body area in Poyang Lake. The order of influence are as follows: Total Population $>$ Gross Fishery Product $>$ Gross Product of Agriculture, Forestry, Livestock and Fishery $>$ Gross Domestic Product per capita $>$ Gross Domestic Product $>$ Floor Space of Buildings Completed.

(4) The results of the principal component analysis indicate that population, economy and urbanization are the first principal components of the Poyang Lake basin, while average annual temperature and average annual precipitation are the second principal component of the Poyang Lake basin. It shows that anthropogenic factors have more influence on Poyang Lake basin than natural factors. Therefore, protective measures should be strengthened to realize the sustainable development of Poyang Lake basin in the future development and utilization process.
Dynamic monitoring of temporal and spatial changes in water bodies using the GEE platform can help more countries and regions understand the changes of the lakes and rivers, and provide technical references for policy and planning. In the future, Poyang Lake water body research will adopt higher temporal and spatial resolution data and more accurate methods to extract water body information.

\section{Acknowledgements}

This research was supported by the National Natural Science Foundation of China (No. 41801308; 41701443); Doctoral Research Fund of Shandong Jianzhu University (No. XNBS1804); and Natural Science Foundation of Shandong Province (No. ZR2018MD008).

\section{Conflict of Interest}

The authors declare no conflict of interest.

\section{References}

1. LI M., LI Y. On the hydrodynamic behavior of the changed river-lake relationship in a large floodplain system, poyang lake (China). Water (Switzerland), 12 (3), $1,2020$.

2. JAVAID A., AHMAD S.R., QADIR A. Health risk surveillance of arsenic in wastewater, groundwater, and agricultural land along Hudaira drain, Pakistan using GIS techniques. Polish Journal of Environmental Studies, 28 (2), 681, 2019.

3. CHEN L., MICHISHITA R., XU B. Abrupt spatiotemporal land and water changes and their potential drivers in Poyang Lake, 2000-2012. ISPRS Journal of Photogrammetry and Remote Sensing, 98, 85, 2014.

4. MICHISHITA R., JIANG Z., XU B. Monitoring two decades of urbanization in the Poyang Lake area, China through spectral unmixing. Remote Sensing of Environment, 117, 3, 2012.

5. LIU Y., WU G., ZHAO X. Recent declines in China's largest freshwater lake: Trend or regime shift? Environmental Research Letters, 8 (1), 2013.

6. ZHANG Q., YE X. chun, WERNER A.D., Li Y. liang, YAO J., LI X. hu, XU C. yu. An investigation of enhanced recessions in Poyang Lake: Comparison of Yangtze River and local catchment impacts. Journal of Hydrology, 517, 425, 2014.

7. SHU W., WANG P., ZHAO J., YU X., XU Q. Characteristics, sources and risk assessment of heavy metals in the Ganjiang river basin, China. Polish Journal of Environmental Studies, 29 (2), 1849, 2020.

8. MANDAL D., KUMAR V., BHATTACHARYA A., RAO Y.S., SIQUEIRA P., BERA S. Sen4Rice: A processing chain for differentiating early and late transplanted rice using time-series sentinel-1 SAR data with google earth engine. IEEE Geoscience and Remote Sensing Letters, 15 (12), 1947, 2018. 
9. HU Q., FENG S., GUO H., CHEN G., JIANG T. Interactions of the Yangtze river flow and hydrologic processes of the Poyang Lake, China. Journal of Hydrology, 347 (1-2), 90, 2007.

10. ZHANG Q., SUN P., CHEN X., JIANG T. Hydrological extremes in the Poyang Lake basin, China: Changing properties, causes and impacts. Hydrological Processes, 25 (20), 3121, 2011.

11. CHENG J., XU L., JIANG M., JIANG J., XU Y. Warming increases nitrous oxide emission from the littoral zone of Lake Poyang, China. Sustainability (Switzerland), 12 (14), $1,2020$.

12. XIE Z., JIANG Y., ZHANG H., WANG,D., QI S., DU Z., ZHANG H. Assessing heavy metal contamination and ecological risk in Poyang Lake area, China. Environmental Earth Sciences, 75 (7), 2016.

13. HUI F., XU B., HUANG H., YU Q., GONG P. International Journal of Remote Modelling spatial temporal change of Poyang Lake using multitemporal Landsat imagery. International Journal of Remote Sensing, 29 (20), 5767, 2008.

14. FENG L., HU C., CHEN X., CAI X., TIAN L., GAN W. Assessment of inundation changes of Poyang Lake using MODIS observations between 2000 and 2010. Remote Sensing of Environment, 121, 80, 2012.

15. HAN X., CHEN X., FENG L. Four decades of winter wetland changes in Poyang Lake based on Landsat observations between 1973 and 2013. Remote Sensing of Environment, 156, 426, 2015.

16. ZENG L., SCHMITT M., LI L., ZHU X.X. Analysing changes of the poyang lake water area using sentinel-1 synthetic aperture radar imagery. International Journal of Remote Sensing, 38 (23), 7041, 2017.

17. GORELICK N., HANCHER M., DIXON M., ILYUSHCHENKO S., THAU D., MOORE R. Google Earth Engine: Planetary-scale geospatial analysis for everyone. Remote Sensing of Environment, 202 (2016), 18, 2017.

18. TELUGUNTLA P., THENKABAIL P., OLIPHANT A., XIONG J., GUMMA M.K., CONGALTON R.G., HUETE A. A 30-m landsat-derived cropland extent product of Australia and China using random forest machine learning algorithm on Google Earth Engine cloud computing platform. ISPRS Journal of Photogrammetry and Remote Sensing, 144 (February), 325, 2018.

19. NYLAND K.E., GUNN G.E., SHIKLOMANOV N.I., ENGSTROM R.N., STRELETSKIY D.A. Land cover change in the lower Yenisei River using dense stacking of landsat imagery in Google Earth Engine. Remote Sensing, $10(8), 2018$.

20. FENG L., HU C., CHEN X., LI R., TIAN L., MURCH B. MODIS observations of the bottom topography and its inter-annual variability of Poyang Lake. Remote Sensing of Environment, 115 (10), 2729, 2011.

21. DUAN W., HE B., NOVER D., YANG G., CHEN W., MENG H., LIU C. Water quality assessment and pollution source identification of the eastern poyang lake basin using multivariate statistical methods. Sustainability (Switzerland), 8 (2), 1, 2016.

22. YESOU H., HUBER C., HAOUET S., LAI X., HUANG S., DE FRAIPONT P., DESNOS Y.L. Exploiting Sentinel 1 time series to monitor the largest fresh water bodies in PR China, the Poyang Lake. International Geoscience and Remote Sensing Symposium (IGARSS), 2016-Novem (July), 3882, 2016.
23. CAI J., ZHANG L., TANG J., PAN D. Adoption of multiple sustainable manure treatment technologies by pig farmers in rural China: A case study of Poyang Lake Region. Sustainability (Switzerland), 11 (22), 2019.

24. WANG Y., MA J., XIAO X., WANG X., DAI S., ZHAO B. Long-term dynamic of Poyang Lake surface water: A mapping work based on the Google Earth Engine cloud platform. Remote Sensing, 11 (3), 2019.

25. ZURQANI H.A., POST C.J., MIKHAILOVA E.A., SCHLAUTMAN M.A., SHARP J.L. Geospatial analysis of land use change in the Savannah River Basin using Google Earth Engine. International Journal of Applied Earth Observation and Geoinformation, 69 (September 2017), 175, 2018.

26. LIU X., TEUBNER K., CHEN Y. Water quality characteristics of Poyang Lake, China, in response to changes in the water level. Hydrology Research, 47, 238, 2016.

27. MCFEETERS S.K. The use of the Normalized Difference Water Index (NDWI) in the delineation of open water features. International Journal of Remote Sensing, 17 (7), $1425,1996$.

28. XU H. Modification of normalised difference water index (NDWI) to enhance open water features in remotely sensed imagery. International Journal of Remote Sensing, 27 (14), 3025, 2006.

29. WANG S., BAIG M.H.A., ZHANG L., JIANG H., JI Y., ZHAO H., TIAN J. A simple enhanced water index (EWI) for percent surface water estimation using landsat data. IEEE Journal of Selected Topics in Applied Earth Observations and Remote Sensing, 8 (1), 90, 2015.

30. FEYISA G.L., MEILBY H., FENSHOLT R., PROUD S.R. Automated Water Extraction Index: A new technique for surface water mapping using Landsat imagery. Remote Sensing of Environment, 140, 23, 2014.

31. WILSON E.H., SADER S.A. Detection of forest harvest type using multiple dates of Landsat TM imagery. Remote Sensing of Environment, 80 (3), 385, 2002.

32. SONG Y., SONG X., SHAO G. Effects of Green Space Patterns on Urban Thermal Environment at Multiple Spatial - Temporal Scales, 2020.

33. YAN C., LIU H., SHENG Y., HUANG X., NIE M., HUANG Q., BAALOUSHA M. Fluorescence characterization of fractionated dissolved organic matter in the five tributaries of Poyang Lake, China. Science of the Total Environment, 637-638, 1311, 2018.

34. LI S.H., JIN B.X., ZHOU J.S., WANG J.L., PENG S.Y. Analysis of the spatiotemporal land-use/land-cover change and its driving forces in Fuxian Lake watershed, 1974 to 2014. Polish Journal of Environmental Studies, 26 (2), 671, 2017.

35. LI D., LAI X., DONG Z., LUO X. Effects of the three Gorges Project on the environment of Poyang Lake. Polish Journal of Environmental Studies, 25 (6), 2477, 2016.

36. LI X., YE X. Spatiotemporal characteristics of dry-wet abrupt transition based on precipitation in Poyang Lake basin, China. Water (Switzerland), 7 (5), 1943, 2015.

37. LI X., ZHANG Q., HU Q., ZHANG D., YE X. Lake flooding sensitivity to the relative timing of peak flows between upstream and downstream waterways: A case study of Poyang Lake, China. Hydrological Processes, 31 (23), 4217, 2017.

38. ZHANG W., CUI C., LI L., JIA Y., MENG L. Analysis of Relationship between Water Area and Water Level Based 
on Long-term Observation in Poyang Lake. Journal of China Hydrology, 39 (3), 29, 2019.

39. QIN H., CAO X., CUI L., LV Q., CHEN T. The Influence of Human Interference on Zooplankton and Fungal Diversity in Poyang Lake Watershed in China. Diversity, 12 (8), 296, 2020.
40. YANG Q., LIU M., HUANG D., XIONG W., YU Q. A Survey and Ecological Risk Assessment of Niclosamide and Its Degradation Intermediate in Wucheng Waters within Poyang Lake Basin. Polish Journal of Environmental Studies, 30 (1), 1, 2021. 
